\title{
Correlation between Beijing-Tianjin-Hebei Transportation Integration and Regional Economy
}

\author{
Wang Miaoxin ${ }^{1}$ \\ ${ }^{1}$ School of Economics and Management Beijing Jiaotong University, BJTU Beijing, China
}

\begin{abstract}
Transportation plays a fundamental role in economic development. Beijing-Tianjin-Hebei is an important economic growth pole. Analyzing and studying the transportation and economic relevance of the region is not only beneficial to the development of region, but also can provide experience examples for the whole country. In this paper, the Coupling model in physics is used to analyze the correlation between transportation integration and regional economy and find that the degree of coupling coordination between the transportation and economic systems in Beijing-Tianjin-Hebei region has been gradually improved.
\end{abstract}

\section{Introduction}

In 2019, the State Council Issued the Program of Building National Strength in Transportation, which outlines the construction of a convenient city transportation network. Studying the correlation between transportation integration and regional economy and make them coordinated is conducive to construction China with strong transportation and achieving economic development. In November 2018, the CPC Central Committee clearly demanded that promoting the coordinated development of Beijing, Tianjin and Hebei and adjusting the regional economic structure and spatial structure. It is necessary to make reasonable and comprehensive adjustment to build a convenient and efficient transportation network, so as to realize the effective diffusion of resources, information and talents from Beijing to Tianjin and Hebei. The diffusion of resources depend largely on the construction of transport infrastructure. On the other hand, if the level of transport infrastructure and the level of economic development is unbalanced, it may exacerbate the siphon effect. Therefore, this paper will discuss the degree of transportation integration and the coupling of Beijing-Tianjin-Hebei regional economy, so as to explore whether the construction of transport infrastructure meets the requirements of Beijing-Tianjin-Hebei coordinated development and whether it can promote the more balanced and reasonable development of regional economy.

Many scholars have done research on analyzing the connection between transportation and economy. Some scholars have carried out relevant analysis using the coupling degree model and the coupling coordination model. Peng Jie[1] believes that there is a coupling interaction between the traffic and economy in Changsha City, and the coupling degree tends to be coordinated;
Zhang Jianjun, Zhao Qilan[2] and Liu Burong[3] studied the correlation between regional logistics capabilities and economic development; Lv Xianhong and Zhang Ruiying[4] analyzed the coupling between tourism and transportation and regional economy. From the perspective of the research area, some scholars have conducted a coupling study on the transportation and economic development level of the third growth pole of Beijing, Tianjin and Hebei, but the conclusions reached are different. Zhai Jingtong[5] used GIS and other methods to draw a conclusion that Beijing-Tianjin-Hebei transportation superiority and industrial structure coupling coordination are overall high and gradually shifting to coordination; Nie Zhengying[6] believed that the coupling coordination degree gradually changed to coordination; Jiao Xiang[7] believes that the coupling coordination in the region has been low, and it is expected that it will fall into a moderate and mild imbalance phase in 2020. Dong Yingying[8] showed that the coordination degree of the two regions depends on the development level of the regional economy. This article will build a coupling analysis model of transportation integration and regional economic coordinated development through the comprehensive development level, coupling degree and coupling coordination degree of transportation and economy, and use the entropy weight method to determine the weight of each indicator. For 2009-2018 BeijingTianjin-Hebei transportation Calculation and empirical analysis of the coupling coordination degree with the regional economy.

\section{Transportation integration and regional economic coupling mechanism}

Coupling degree reflects the degree of interdependence and mutual influence between the system and elements. On the one hand, transportation promotes the development of economy. First of all, transportation integration can 
provide guarantee for passenger and cargo transportation generated by economic activities and stimulate economic development. In addition, transportation can influence and drive the adjustment of economic and industrial structure and promote economic development through agglomeration effect, diffusion effect and multiplier effect. However, the social cost of transportation will also restrain economic development through negative effects. On the other hand, the economy has a pulling effect on the development of transportation. With the expansion of the economic market, it is necessary to improve the transport system. Therefore, the two are interdependent and mutually reinforcing. The coupling mechanism is shown in Figure 1 below.

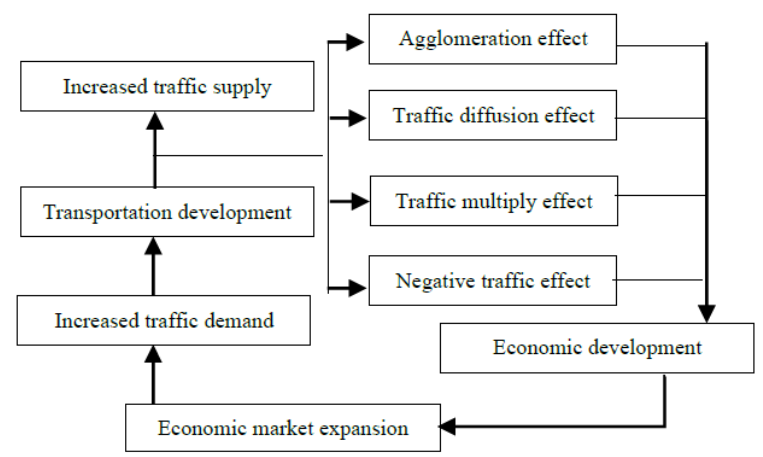

Fig1. The coupling mechanism of transportation and economy

\section{Transportation Integration and Regional Economic Development Status}

The Beijing-Tianjin-Hebei region has a total population of 112.7 million in 2018. According to statistics on the official website of the National Bureau of Statistics, the Beijing-Tianjin-Hebei region transported 1,237.3 million passengers, accounting for 7.0 percent of China's total passenger volume, and 3224.16 million tons of cargo, accounting for 6.3 percent of China's total cargo volume. The length of railways in operation is $9779 \mathrm{~km}$, accounting for $7.4 \%$ of the total length of railways in China. The length of highways is $231,764 \mathrm{~km}$, accounting for $4.8 \%$ of the total length of highways in China, of which the length of expressways is $9,656 \mathrm{~km}$.

\section{Coordination model of coupling of transportation integration and regional economy}

\subsection{Construction of evaluation index system}

\subsubsection{Construction of evaluation index system}

According to Dong Dapeng[9], this paper draws on the relevant research results of transportation integration, based on the actual situation of Beijing-Tianjin-Hebei, and comprehensively considers the availability of the data, and selects 7 specific evaluation indicators. The details are shown in the table 1:
Table1. Evaluation Index System of Transportation System in Beijing-Tianjin-Hebei Region

\begin{tabular}{|c|c|c|}
\hline dimension & index & symbol \\
\hline \multirow{2}{*}{$\begin{array}{c}\text { Transportation } \\
\text { layout }\end{array}$} & Railway operating mileage $(\mathrm{km})$ & $\mathrm{x}_{1}$ \\
\hline & Highway operating mileage $(\mathrm{km})$ & $\mathrm{x}_{2}$ \\
\hline \multirow{4}{*}{$\begin{array}{l}\text { Transportation } \\
\text { scale }\end{array}$} & $\begin{array}{l}\text { Total passenger traffic (ten thousand } \\
\text { people) }\end{array}$ & $\mathrm{x}_{3}$ \\
\hline & Total freight volume ( 10,000 tons) & $\mathrm{x}_{4}$ \\
\hline & $\begin{array}{l}\text { Total passenger turnover (100 million } \\
\text { person kilometers) }\end{array}$ & $\mathrm{x}_{5}$ \\
\hline & $\begin{array}{c}\text { Total cargo turnover (100 million tons } \\
\text { kilometers) }\end{array}$ & $\mathrm{x}_{6}$ \\
\hline $\begin{array}{l}\text { Transportation } \\
\text { investment }\end{array}$ & $\begin{array}{l}\text { Transportation investment (100 million } \\
\text { yuan) }\end{array}$ & $\mathrm{x}_{7}$ \\
\hline
\end{tabular}

\subsubsection{Evaluation Index of economic system}

For the regional economic system, this paper selects 9 indicators to measure the development level of the economic system. The details are shown in the table 2:

Table2. Evaluation Index System of Economic System in Beijing-Tianjin-Hebei Region

\begin{tabular}{ccc}
\hline dimension & index & symbol \\
\hline \multirow{4}{*}{ Economic scale } & Regional GDP (100 million yuan) & $\mathrm{y}_{1}$ \\
& Total social fixed asset investment (100 million yuan) & $\mathrm{y}_{2}$ \\
& Import and export (100 million US dollars) & $\mathrm{y}_{3}$ \\
& General budget revenue (100 million yuan) & $\mathrm{y}_{4}$ \\
Economic & Total retail sales of social consumer goods (100 & $\mathrm{y}_{5}$ \\
structure & million yuan) & $\mathrm{y}_{6}$ \\
& The proportion of tertiary industry (\%) & $\mathrm{y}_{7}$ \\
Economic & Number of graduates (person) & $\mathrm{y}_{8}$ \\
quality & Education expenditure (100 million yuan) & $\mathrm{y}_{9}$ \\
\hline & Number of authorized invention patent applications & (pieces) \\
\hline
\end{tabular}

\subsection{Coupling coordination model}

Coupling degree indicates the degree of influence of the interaction between systems or elements. There is a mutually promoting and coordinated relationship between transportation integration and regional economy. This paper draws on the coupling model combined with physics and related achievements in the field of economics. The main steps of the coupling model of the transport system and the regional economic system are as follows:

\subsubsection{Standardization}

Let $\mathrm{x}_{\mathrm{i}}$ denote the evaluation index of the transport subsystem, and $y_{i}$ denote the evaluation index of the regional economic subsystem. Because the meaning and dimension of each indicator are different, it needs to be standardized. This article adopts the MIN-MAX standardization method. For example, for the transport system, the calculation formula (1) is:

$$
X_{i}=\frac{x_{i}-x_{\min }}{x_{\max }-x_{\min }}
$$

$X_{i}$ is a dimensionless value, and $x_{\min }$ and $x_{\max }$ are the minimum and maximum values of each evaluation index in all years. 


\subsubsection{Entropy weight method}

This article uses the entropy weight method in the objective evaluation method to weight each evaluation index. The entropy weight method determines the weight of the indicators based on the degree of correlation between the indicators and the amount of information provided by the indicators. Specific steps are as follows:

Normalize the indicators:

$$
X_{i}^{\prime}=\frac{X_{i}}{\sum X_{i}}
$$

Calculate the entropy value of each index:

$E_{i}=-\sum X_{i}^{\prime} \ln X_{i}^{\prime}$

$a_{i}=\frac{\max E_{i}}{E_{i}}$

Calculate the weight of each indicator:

$a_{i}=\frac{\max _{i}}{E_{i}}$

\subsection{The comprehensive development level of the subsystem}

If $X=\left(x_{1}, x_{2}, \ldots, X_{n}\right)$ represents $n$ indicators of the transport system, and $Y=\left(y_{1}, y_{2}, \ldots, y_{m}\right)$ represents $m$ indicators of the economic system, then on the basis of index standardization and weighting, To construct the formula for calculating the comprehensive development level of each subsystem:

$$
F(x)=\sum_{i=1}^{n} w_{i} X_{i} ; F(y)=\sum_{j=1}^{m} w_{j} Y_{j}
$$

\subsubsection{System coupling}

This paper studies the coupling between the two subsystems of transport system and regional economy, so the calculation formula is:

$$
C=2 \sqrt{\frac{F(x) \times F(y)}{(F(x)+F(y))^{2}}} ; c \in(o, 1)
$$

Among them, $\mathrm{C}$ is the degree of coupling between the transport system and the regional economic system. The greater the degree of coupling, the more coordinated the two are.

\subsubsection{System coupling coordination}

The coordination degree model measures the coupling coordination degree of transportation integration and regional economy. The calculation formula of the comprehensive evaluation index $\mathrm{F}$ and coupling coordination degree $\mathrm{D}$ of the coupled system is:

$$
\begin{aligned}
& F=\alpha F(x)+\beta F(y) \\
& D=\sqrt{C \times F}
\end{aligned}
$$

This paper refers to the research of Jiao Xiang and others, and regards the transport system and regional economy as equally important subsystems, so $\alpha$ and $\beta$ are

\begin{tabular}{|c|c|c|c|}
\hline D & $\begin{array}{c}\text { Coordination } \\
\text { degree }\end{array}$ & D & Coordination degree \\
\hline $0-0.09$ & Extreme disorder & $0.50-0.59$ & Barely coordinated \\
\hline $0.10-0.19$ & Severe disorder & $0.60-0.69$ & Primary coordination \\
\hline $0.20-0.29$ & Moderate disorder & $0.70-0.79$ & $\begin{array}{l}\text { Intermediate } \\
\text { coordination }\end{array}$ \\
\hline $0.30-0.39$ & Mild disorder & $0.80-0.89$ & Well coordinated \\
\hline $0.40-0.49$ & $\begin{array}{l}\text { Imminent } \\
\text { imbalance }\end{array}$ & $0.90-1$ & Quality coordination \\
\hline
\end{tabular}
both 0.5 , and the coupling coordination degree is divided as follows:

Table3. Classification standard of coupling coordination degree

According to the coupling coordination degree model, if the development level of the two coupling subsystems is close, that is, the closer the development indexes of transportation and regional economy are, the higher the coupling coordination degree will be.

\section{An Empirical Analysis of Transportation Integration and Economic Coupling}

\subsection{Data and standardization}

The data comes from the official website of the National Bureau of Statistics, China Statistical Yearbook, and the Statistical Yearbook of Beijing, Tianjin and Hebei Province.

\subsection{Calculation result of entropy weight method}

\subsubsection{Traffic system entropy weight result}

Table4. Traffic system entropy weight result and Regional economic entropy weight result

\begin{tabular}{cccccc}
\hline Index symbol & Entropy & Weight & Index symbol & Entropy & Weight \\
\hline $\mathrm{y} 1$ & 2.0900 & 0.1231 & $\mathrm{x} 1$ & 1.9650 & 0.1339 \\
\hline $\mathrm{y} 2$ & 2.4538 & 0.1048 & $\mathrm{x} 2$ & 2.0424 & 0.1288 \\
\hline $\mathrm{y} 3$ & 2.7685 & 0.0929 & $\mathrm{x} 3$ & 1.4981 & 0.1756 \\
\hline $\mathrm{y} 4$ & 2.5183 & 0.1022 & $\mathrm{x} 4$ & 2.3177 & 0.1135 \\
\hline $\mathrm{y} 5$ & 2.4392 & 0.1055 & $\mathrm{x} 5$ & 1.6599 & 0.1585 \\
\hline $\mathrm{y} 6$ & 1.7535 & 0.1467 & $\mathrm{x} 6$ & 1.5317 & 0.1718 \\
\hline $\mathrm{y} 7$ & 2.6949 & 0.0955 & $\mathrm{x} 7$ & 2.2342 & 0.1178 \\
\hline $\mathrm{y} 8$ & 2.3035 & 0.1117 & & & \\
\hline $\mathrm{y} 9$ & 2.1860 & 0.1177 & & & \\
\hline
\end{tabular}


It can be seen from Table 4 that the greater the entropy value of the indicator, the smaller its weight. It can be seen from the results that the higher weights in the transport system are passenger traffic, freight turnover and passenger turnover, but the weights of the indicators are not much different.
It can be seen from Table 4 that regional GDP accounts for the largest influence. However, the impact of the number of graduates, education funding, and number of patent grants may be more difficult to measure because it measures the quality and potential of economic development.

\subsubsection{Regional economic entropy weight result}

\subsection{Calculation of coupling coordination}

Table5. Subsystem development level, coupling degree and coupling coordination degree

\begin{tabular}{ccccccc}
\hline year & Fx & Fy & $\mathbf{C}$ & $\mathbf{F}$ & $\mathbf{D}$ & Coordination degree \\
\hline 2009 & 0.1647 & 0.0000 & 0.0000 & 0.0823 & 0.0000 & Extreme disorder \\
2010 & 0.4120 & 0.1278 & 0.8502 & 0.2699 & 0.4791 & Imminent imbalance \\
2011 & 0.6008 & 0.2822 & 0.9326 & 0.4415 & 0.6417 & Primary coordination \\
2012 & 0.6759 & 0.3637 & 0.9538 & 0.5198 & 0.7042 & Intermediate coordination \\
2013 & 0.3376 & 0.5113 & 0.9788 & 0.4245 & 0.6446 & Primary coordination \\
2014 & 0.4505 & 0.6094 & 0.9887 & 0.5300 & 0.7239 & Intermediate coordination \\
2015 & 0.3963 & 0.6997 & 0.9609 & 0.5480 & 0.7257 & Intermediate coordination \\
2016 & 0.4318 & 0.8022 & 0.9539 & 0.6170 & 0.7672 & Intermediate coordination \\
2017 & 0.5225 & 0.8994 & 0.9642 & 0.7109 & 0.8279 & Well coordinated \\
2018 & 0.6056 & 0.9910 & 0.9704 & 0.7983 & 0.8802 & Well coordinated \\
\hline
\end{tabular}

\subsection{Results analysis}

First, as can be seen from Figure 2, except for the 2013 data fluctuations (different statistical calibers), the Beijing-Tianjin-Hebei transportation integration has steadily increased, and development in good condition. The correlation coefficient analysis of the comprehensive evaluation value found that the correlation coefficient of the two is as high as 0.88 , and there is a significant correlation, indicating that there is a coupling and interactive development relationship between BeijingTianjin-Hebei transportation integration.

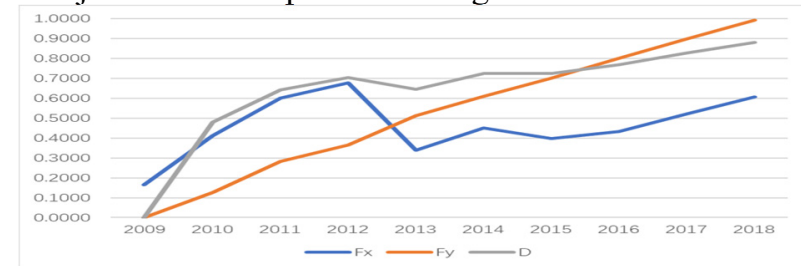

Fig2. Beijing-Tianjin-Hebei transportation integration and regional economic comprehensive development level and coupling coordination degree

Second, as can be seen from Table 5, the coupling coordination level has gradually changed from imbalance to coordination. Generally, it is divided into two stages. The first stage is the imbalance stage from 2009 to 2010 , and the second stage is the coordination stage from 2011 to 2018. This shows that the Beijing-Tianjin-Hebei region has coordinated development of transportation and regional economy before 2010 . The effect is weak, and the promotion effect between each other is not obvious; the coupling interaction effect of the two systems has gradually strengthened, especially in 2017, the coupling coordination between the two systems has been significantly improved, achieving good coordination, and showing a growth trend, indicating that the coordination of Beijing-Tianjin-Hebei transportation integration and the regional economy is getting better and better, and the two have achieved mutual promotion and mutual development.

Third, in 2013 the ratio of the comprehensive development level of the transport system to the level of the regional economic system changed. The similar level of development of the two systems can be calculated by the ratio of the two system index. The closer the ratio is to 1 , the closer the coupled development level is. Before 2013, the ratio of the transportation development level to the regional economy was greater than 1 , indicating that the region was an advanced development type of transportation; after 2013, the ratio of the transportation development level to the regional economy was less than 1 , indicating that the region became a transportation development type. Before 2013, the transport system in the Beijing-Tianjin-Hebei region was ahead of economic development, and the growth rate of the coupling coordination degree was high, indicating that the moderately advanced development of the transport system can make the regional economy better coordinated development.

Fourth, since 2013 although the degree of coupling coordination has been increasing, the growth rate has slowed down, combined with the lag in the development of the transport system, it can be considered that the relationship between transportation and regional growth should be further coordinated, and transportation development should be optimized to match and adapt to the level of economic development.

\section{Summary}

There is a mutual influence and restriction relationship between transportation and regional economy, and the degree of coupling coordination is an important index to measure their mutual relationship. If the degree of coupling and coordination is high, the two can promote each other's coordinated development. Backward transportation will restrain economic development to different degrees. In this paper, using the coupled coordination degree model, the 
entropy weight method to various indicators of empowerment, and statistics 2009-2018 to calculate the transportation integration of the Beijing-Tianjin-Hebei region and coupling coordination degree of the regional economic development, analyzes the Beijing-TianjinHebei in recent years, traffic and regional economic integration of the coupling, the coupling although there are fluctuations, but overall is increase steadily, and coupling coordination level gradually from disorder to the coordinate transformation, especially the coupling coordination degree in 2017 achieved good coordination, and present a growth trend.

\section{Acknowledgment}

First of all, I would like to thank my teacher with my most sincere respect. The teacher's rigorous academic attitude, profound theoretical knowledge and patient guidance enabled me to complete this article. Secondly, I would like to thank the judges for their valuable comments

\section{References}

1. Peng Jie. Research on the Coupling and Coordination of Regional Traffic and Urban Development in Changsha. Hunan Normal University,2019.

2. Zhang Jianjun, Zhaoqilan, Liu Guiyan. Research on Coupling Interaction Mechanism between Regional Logistics Capability and Regional Economic Development. Journal of Mathematics in Practice and Theory,2019,49(12):50-60.

3. Liu Burong. Study on the Cooperative Development of Regional Logistics and Regional Economy in Jiangsu Province. Anhui University of Science and Technology,2019.

4. Lv Xianhong, Zhang Ruiying. Empirical Study on the Coupling and Coordination Relationship of TourismTraffic-Regional Economy: Based on the Provincial Panel Data of Silk Road Economic Belt. Editorial Department of Journal of Neijiang Normal Univesity, 2019(6).

5. Zhai Jingtong. Study on the Coupling Relation between Urban Transportation Superiority and Industrial Connection in Beijing-Tianjin-Hebei[D]. Tianjin Chengjian University,,2017.

6. Nie Zhengying, Li Ping. Analysis of Coupling and Coordination between Beijing-Tianjin-Hebei Transportation Integration and Regional Economy Based on Entropy Method. CHINA TRANSPORTATION REVIEW, 2019(4):37-42.

7. Jiao Xiang. Coupling Research on Transportation and Regional Economic Development-Comparative Analysis Based on Beijing-Tianjin-Hebei and Yangtze River Delta. Beijing Jiaotong University,2019.

8. Dong Yingying. Research on Domestic Integrated Transport and Regional Economic Development. Beijing Jiaotong University,2011.
9. Dong Dapeng. The Impact of Transportation to Regional Economy Development-Analysis Based on Jilin Province. Northeast Normal University.2010. 